This is the final peer-reviewed accepted manuscript of:

Sapino, Simona; Oliaro-Bosso, Simonetta; Zonari, Daniele; Zattoni, Andrea; Ugazio, Elena. Mesoporous silica nanoparticles as a promising skin delivery system for methotrexate. International Journal of Pharmaceutics 530 (1-2), 239-248, 2017.

The final published version is available online at:

http://dx.doi.org/10.1016/j.ijpharm.2017.07.058

Rights / License:

The terms and conditions for the reuse of this version of the manuscript are specified in the publishing policy. For all terms of use and more information see the publisher's website.

This item was downloaded from IRIS Università di Bologna (https://cris.unibo.it/)

When citing, please refer to the published version. 


\section{MESOPOROUS SILICA NANOPARTICLES AS A PROMISING SKIN DELIVERY SYSTEM FOR METHOTREXATE}

Simona Sapino ${ }^{\mathrm{a}, \mathrm{b}, \mathrm{c}}$, Simonetta Oliaro-Bosso ${ }^{\mathrm{a}, \mathrm{c}}$, Daniele Zonari ${ }^{\mathrm{a}}$, Andrea Zattoni ${ }^{\mathrm{d}, \mathrm{e}}$ and Elena Ugazio $^{\mathrm{a}, \mathrm{b}, \mathrm{c} *}$

${ }^{a}$ Università di Torino, Dipartimento di Scienza e Tecnologia del Farmaco, Via P. Giuria 9, 10125 Turin, Italy.

${ }^{b}$ NIS (Nanostructured Interfaces and Surfaces) Centre, Università di Torino, Turin, Italy.

c“G. Scansetti” Interdepartmental Centre, Università di Torino, Turin, Italy.

${ }^{d}$ Dipartimento di Chimica "G. Ciamician", Via Selmi 2, 40126 Bologna.

ebyFlow Srl, Via Caduti della Via Fani 11/b, 40127.

*Corresponding author: Tel: +39 0116707192; Fax: +39 0116707162

E-mail address: elena.ugazio@unito.it

Keywords: MCM-41 nanoparticles, skin disorders, cutaneous application, keratinocyte cells, epidermal accumulation, shea butter 


\section{ABSTRACT}

The systemic administration of methotrexate (MTX), a commonly used, antineoplastic drug which is also used in cutaneous disorders, is primarily associated with prolonged retention in the body and consequently with side effects. Innovative drug delivery techniques and alternative administration routes would therefore contribute to its safe and effective use. The general objective of this study is thus the development of MTX-based preparations for the topical treatment of skin disorders. MCM41-like nanoparticles (MSN), are herein proposed as carriers which can improve the cutaneous absorption and hence the bioavailability and efficacy of MTX. The MTX/MSN complex, prepared via the impregnation procedure, has been physico-chemically characterized, while its cell cultures have had their biocompatibility and bioactivity tested. Furthermore, a series of stable MTX-based dermal formulations has been developed, some containing shea butter, a natural fat. Ex-vivo porcine skin absorption and the transepidermal permeation of MTX have also been monitored in a variety of media using Franz diffusion cells. Interestingly, the epidermal accumulation of the active molecule was increased by its inclusion into MSN, regardless of the surrounding medium. Furthermore, the presence of shea butter enhanced the skin uptake of the drug both in the free and in the loaded form. 


\section{Introduction}

Methotrexate (MTX), a synthetic folic acid antagonist, is a well-known drug that presents cytotoxic activity (Abbaszad Rafi et al., 2016; Hess and Khasawneh, 2015), and is frequently used as a chemotherapeutic agent for the treatment of a number of cancers, including breast, head and neck, leukemia, lymphoma, lung and osteosarcoma (Kim et al., 2012; Pan et al., 2016). Its efficacy has also been demonstrated in the treatment of inflammatory processes, such as rheumatoid arthritis (Curtis et al., 2016), and more recently Bowel and Crohn's diseases (Cipriani et al., 2014a; Herfarth et al., 2016). Moreover, psoriasis and other skin diseases are regularly treated via the systemic administration of MTX, either alone or in association with other drugs (Quist et al., 2016, Yélamos et al., 2015).

Its relatively low cost and favorable efficacy/safety profile mean that MTX is currently seeing widespread use. Besides its benefits, it can unfortunately also be a source of unwanted effects (including mucocutaneous and gastrointestinal intolerance and hepatic and pulmonary toxicity), (Yélamos et al., 2014).

MTX therapy optimization is therefore a priority, particularly with a view to uncover the ideal treatment strategy and administration route (Cipriani et al., 2014b; Li et al., 2016). MTX is generally systemically administered weekly in the treatment of psoriasis, at regimens not exceeding 25 mg/week (Yélamos et al., 2014), via a number of routes; intravenous, intramuscular and oral. However, it is rarely administered topically via the skin, despite the fact that this route may be able to prevent the occurrence of the side effects and toxicity typically associated with the systemic application of this agent. One of the major problems with the cutaneous route is the drug's solubility in water and the fact that it is mostly present in the ionized form at physiological $\mathrm{pH}$, meaning that its capacity for skin absorption via passive diffusion across the stratum corneum (SC) is limited (Alvarez-Figueroa and Blanco-Méndez, 2001).

The development of formulations that are able to increase the local bioavailability of MTX can 
therefore offer a plausible means for safe administration. It has been demonstrated that an MTX preparation, containing an appropriate surfactant $\left(\right.$ Transcutol $\left.^{\circledR}\right)$, and combined with salicylic acid, can be clinically used for local treatment of psoriasis (Javadzadeh and Hamishehkar, 2011). Other researchers have recently shown that the transcutaneous administration of a nanostructured-lipidcarrier based gel formulation, loaded with MTX, is able to decrease inflammation in an animal model of arthritis with minimal adverse effects (Garg et al., 2016).

Nano-carriers generally help to increase drug solubility, confer protection against degradation, improve efficacy and reduce side effects by enhancing and targeting bioavailability.

Polyethylene glycol-coated silver nanoparticles (Muhammad et al., 2016), and sandwich-like mesoporous silica nanoflakes (Peruzynska et al., 2016), have been proposed as a promising delivery systems that can improve anticancer efficacy and decrease MTX side effects. Similarly, $\mathrm{pH}-$ responsive, mesoporous nanosilica MCM-41 may be an appropriate candidate for MTX delivery to cancerous tissues (Abbaszad Rafi et al., 2016). MCM-41 silica has also been compared with other mesoporous materials for the oral drug delivery of MTX (Alexa et al., 2013). However, MSN have not yet been tested as an MTX delivery system for skin applications, to the best of our knowledge. The well-known properties of silica, mesostructured MCM-41 type nanoparticles, namely high surface area (around $\left.1000 \mathrm{~m}^{2} \mathrm{~g}^{-1}\right)$, tunable pore dimensions $(20-40 \mathrm{~nm}$ ), their uniform hexagonal porous structure, thermal stability and biocompatibility (Vallet-Regí et al., 2007), make them promising candidates for the delivery of pharmaceutical molecules. Moreover, recent reports, including our own studies (Sapino et al., 2015; Ugazio et al., 2016), have shown that MSN can be efficiently used as a drug delivery system for topical applications.

The main aim of this work is therefore to determine the feasibility of MSN's use as a storage and transport material which can favor the accumulation of MTX in the skin and offer an alternative administration route for the treatment of several cutaneous disorders.

As reported above, the main difficulty in developing an MTX topical formulation is its low lipophilicity, which results in fruitless dermal accumulation. In order to address this important issue, 
the present study reports the preparation of a complex between MTX and MSN, achieved using an appropriate impregnation method. Physico-chemical characterization has been carried out, while the biocompatibility of the vehicle and the efficacy of the complex have been investigated in vitro on a human epidermal keratinocyte cell line ( $\mathrm{HaCaT})$. Finally, skin penetration properties have also been investigated. To this aim, ex-vivo tests, performed on porcine skin using Franz cells, have shown that the epidermal accumulation of loaded MTX by silica nanoparticles is higher than that of the pure drug, highlighting the enhancing effects of shea butter.

Overall, the results of this present work can pave the way for the replacement of the systemic route of administration, largely employed for MTX, with local noninvasive skin applications that can reduce side effects and increase patient compliance.

\section{Materials and Methods}

\subsection{Materials}

Absolute ethanol, ammonium acetate and acetonitrile were purchased from Fluka. Montanov ${ }^{\circledR} 68$ (Cetearyl Alcohol and Cetearyl Glucoside), Glycerin, Cetiol ${ }^{\circledR} \mathrm{S}$ (Diethylhexylcyclohexane), Amphisol $\mathrm{K}^{\circledR}$ (Potassium Cetyl Phosphate), Phenoxyethanol, Methylparaben, Butylparaben, Ethylparaben and Propylparaben were obtained from Farmalabor. Dehymuls PGPH ${ }^{\circledR}$ (Polyglyceryl 2-Dipolyhydroxystearate), was obtained from BASF. Tegosof ${ }^{\circledR}$ CI (Cetearyl Isononanoate), was obtained from Evonik and Nesatol ${ }^{\circledR}\left(\mathrm{C}_{10-18}\right.$ Triglycerides), from Vevy Europe. Paraffinum Liquidum, $\mathrm{Abil}^{\circledR} 350$ (Dimethicone), Kemipur $100^{\circledR}$ (Imidazolidinyl urea), Mineral oil, Lanolin Alcohol, Helianthus Annuus Seed Oil and Glycine Soja Oil were purchased from A.C.E.F.

Butyrospermum Parkii butter (shea butter), was kindly provided by Dr. Carlotta Castagnoli, while the Novachem surfactant was kindly provided by Postnova.

MTX, Dimethyl sulfoxide (DMSO), potassium dihydrogen phosphate, di-sodium hydrogen phosphate, magnesium sulphate, sodium chloride, sulforhodamine B (SRB), DMEM medium, fetal calf serum, Tris buffered saline, trichloroacetic acid and antibiotics for cell cultures were all 
purchased from Sigma-Aldrich. The HaCaT cell line was kindly provided by Dr. Carlotta Castagnoli (Dipartimento di Chirurgia Generale e Specialistica, Banca della Cute, AOU Città della Salute e della Scienza di Torino, Italy).

\subsection{Characterization of MSN}

High-resolution transmission electron microscopy (HRTEM), observations were performed on a JEOL 3010 instrument operating at $300 \mathrm{kV}$. Sample powders were dispersed on a copper grid coated with a perforated carbon film for the measurements.

Scanning electron microscopy (SEM), images of MSN were obtained using a Stereoscan 410 (Leica). MSN specimens from water dispersions were prepared by pouring a few drops of the MSN suspension $(1.0 \mathrm{mg} / \mathrm{mL})$, onto an aluminum stub and were imaged after complete evaporation of the solvent.

The hydrodynamic diameter (HD) of MSN was examined using an AF2000 Asymmetric Flow FieldFlow Fractionation (AF4), instrument (Postnova), which was coupled online to a SPD-20A UV-Vis spectrophotometer (Postnova), and a Zetasizer Nano ZS (Malvern Instruments). Field-Flow Fractionation (FFF) was carried out with a regenerated cellulose membrane (cut off $10 \mathrm{kDa}$ ) and with a spacer of $350 \mu \mathrm{m}$. Milli-Q ${ }^{\circledR}$ water, containing a $0.1 \% \mathrm{w} / \mathrm{v}$ Novachem surfactant (filtered through $0.1 \mu \mathrm{m}$ membrane), was used as the carrier. Manual injection was performed using a $20 \mu \mathrm{L}$ loop and 6 min focusing time (tip flow $0.2 \mathrm{~mL} \mathrm{~min}^{-1}$, focus flow $1.3 \mathrm{~mL} \mathrm{~min}^{-1}$ ). Each sample was sonicated using an ultrasonic probe device prior to injection to ensure the homogeneous distribution of suspended particles.

The flow rate to the detector was kept at $0.5 \mathrm{~mL} \mathrm{~min}^{-1}$ for elution, while a cross flow, starting from

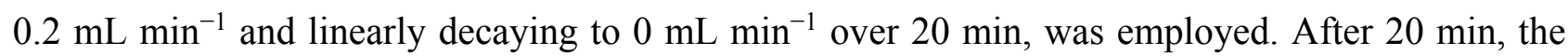
cross flow was kept at $0 \mathrm{~mL} \mathrm{~min}^{-1}$ for a further $20 \mathrm{~min}$ in order to remove any residual particles from the separation channel (40 min total run time).

Zeta potential measurements of MSN and MTX/MSN were performed using electrophoretic light scattering (Zetasizer Nano ZS, Malvern Instruments). Each system was suspended in ultra-filtered 
water $(0.1 \% \mathrm{w} / \mathrm{v})$, sonicated for $10 \mathrm{~min}$ and then analyzed at $25 \pm 0.1{ }^{\circ} \mathrm{C}$.

\subsection{MTX loading}

The loading of MTX inside MSN pores was carried out using the impregnation method at a $1 / 1 \mathrm{w} / \mathrm{w}$ ratio. A weighed amount $(60 \mathrm{mg})$ of $\mathrm{MSN}$ was added to $4 \mathrm{~mL}$ of DMSO, containing $15 \mathrm{mg} / \mathrm{mL}$ of MTX. The mixture was kept in the dark under magnetic stirring at $40{ }^{\circ} \mathrm{C}$ for $24 \mathrm{~h}$, after which the dispersion was added to $36 \mathrm{~mL}$ of distilled water to promote precipitation. The suspension was centrifuged, dried under vacuum and then subjected to a washing run; the dry powder was dispersed in $3 \mathrm{~mL}$ of $\mathrm{pH} 6.5$ phosphate buffer, stirred for few seconds, centrifuged and dried under vacuum. The resultant complex, hereafter labeled as MTX/MSN, was recovered and kept under an inert $\mathrm{N}_{2}$ atmosphere.

The quantitative loading of MTX was determined via extraction with either DMSO or phosphate buffer ( $\mathrm{pH}$ 6.5), as follows; a weighed amount (2.0 mg), of MTX/MSN was added to $10 \mathrm{~mL}$ of each medium and magnetically stirred for $24 \mathrm{~h}$ in the dark at $20^{\circ} \mathrm{C}$. The mixture was then centrifuged and analyzed using a DU 730 UV/Vis Spectrophotometer (Beckman Coulter).

\subsection{In vitro MTX release study}

The release of MTX from the loaded MSN was investigated using glass apparatus consisting of two horizontal cells (each of $12 \mathrm{~mL}$ volume), separated by a Servapor ${ }^{\circledR}(12,000-14,000$ MWCO, Serva Electrophoresis), cellulose dialysis membrane $\left(2.92 \mathrm{~cm}^{2}\right.$ diffusion area). The donor phase consisted of a dispersion of MTX/MSN in phosphate buffer ( $\mathrm{pH}$ 6.5), while the receiving phase was pure phosphate buffer ( $\mathrm{pH}$ 6.5). A solution of free MTX, used at the same concentration, was also tested as a control. The apparatus was placed in an incubator at $34 \pm 1^{\circ} \mathrm{C}$, roughly the same temperature as human skin, for the runs.

At fixed times, up to $24 \mathrm{~h}$, an aliquot of the receiving phase was withdrawn, replaced with an equal volume of fresh medium, centrifuged and analyzed using UV-Vis spectrophotometry at $\lambda_{\max }=301$ 
$\mathrm{nm}$. The results of the release test are reported as the percentage of released MTX vs time, calculated from the total amount of MTX in the donor phase.

The experiments were performed in duplicate and the error bar of each point is denoted by the confidence interval.

\subsection{Cell proliferation assay}

MSN biocompatibility and the efficacy of the MTX/MSN system were evaluated using a sulforhodamine B colorimetric proliferation assay (SRB assay), in a HaCaT cell line. Cells were routinely grown in DMEM with the addition of $10 \%(\mathrm{v} / \mathrm{v})$ fetal calf serum, $1 \%(\mathrm{v} / \mathrm{v})$ penicillin-streptomycin and were maintained in standard conditions $\left(37{ }^{\circ} \mathrm{C}, 5 \% \mathrm{CO}_{2}\right.$ and $95 \%$ humidity). For cell proliferation assays, MTX, MTX/MSN and bare MSN were pre-suspended in the culture medium which contained $1 \%(\mathrm{v} / \mathrm{v})$ ethanol. Ten thousand cells were seeded into 96-well plates. After $24 \mathrm{~h}$, cells were incubated for either $48 \mathrm{~h}$ or $72 \mathrm{~h}$, in triplicate wells with the following samples, all diluted in culture medium; (i) $1 \mathrm{nM}, 10 \mathrm{nM}, 100 \mathrm{nM}, 1000 \mathrm{nM}, 10000 \mathrm{nM}$ MTX; (ii) MTX/MSN amounts containing the same MTX concentrations as (i); (iii) MSN in the same amounts as present in the complex (ii), namely: $0.665,6.65,66.5,665,6650 \mathrm{ng} / \mathrm{mL}$. Control cells were incubated with the culture medium which contained the same final concentration of ethanol (maximum concentration $0.5 \% \mathrm{v} / \mathrm{v}$ ). The SRB assays were carried out as previously described (Sapino et al., 2015; Ugazio et al., 2016). The experiment was replicated twice for both incubation times.

\subsection{Ex-vivo experiments}

\subsubsection{Preparation of dermal formulations}

The ex-vivo study of percutaneous absorption was carried out using a variety of media (Table 1), as the topical vehicles for MTX, whether free or loaded in MSN. An appropriate amount of MTX, or MTX/MSN, was added to ensure an active agent final concentration of $0.6 \% \mathrm{w} / \mathrm{w}$ for all the 
preparations. Pure shea butter and glycerolipidic lotions were simply obtained via the magnetic stirring of the components at $35^{\circ} \mathrm{C}$ (shea butter melting point). Emulsion systems were prepared by properly combining the ingredients of phase A and phase B under homogenization with a T-25 Ultra$\operatorname{Turrax}^{\circledR}$ homogenizer (IKA Instruments), at 15,000 rpm for 5 minutes. Phosphate buffer (pH 6.5), was also tested as a reference medium.

\subsubsection{Franz cell experiments}

Skin uptake and transepidermal permeation were determined using vertical Franz diffusion cells placed in an incubator at $34 \pm 1{ }^{\circ} \mathrm{C}$, with the compartments held together using a clamp. Thin slices of porcine epidermis, isolated using an $\operatorname{Acculan}^{\circledR}$ dermatome (Aesculap), and treated as previously reported (Sapino et al., 2015, Ugazio et al. 2016), were used. An appropriate aliquot (250 $\mu \mathrm{L})$, of each formulation, containing either free or complexed $0.6 \% \mathrm{w} / \mathrm{w}$ MTX, was applied to the skin surface and carefully spread to achieve complete uniform coverage, with a diffusion area of $1.60 \mathrm{~cm}^{2}$. The receptor medium consisting in phosphate buffer $(\mathrm{pH}$ 6.5) was continuously mixed using a magnetic stirring bar over the entire measurement period. Proper aliquots were withdrawn for MTX determination at regular time intervals $(1-24 \mathrm{~h})$, and the cell was immediately refilled with fresh receptor solution. At the end of the experiment $(24 \mathrm{~h})$, the application site of the skin was washed with normal saline solution $(0.9 \% \mathrm{w} / \mathrm{v}$ sodium chloride), to remove the residual formulation on the surface. The skin was then cut into small pieces with a scalpel and $2.0 \mathrm{~mL}$ of a phosphate buffer $(\mathrm{pH}$ 6.5)/DMSO (90/10 v/v), mixture was added for MTX extraction. After $24 \mathrm{~h}$ of magnetic stirring at room temperature (RT), the resulting suspension was centrifuged and the supernatant was analyzed by HPLC apparatus (Shimadzu), employing an UV-Vis detector fixed at $301 \mathrm{~nm}$, a Purospheres Star RP-C18 endcapped column (Merck, $150 \times 4.6 \mathrm{~mm} ; 5 \mu \mathrm{m}$ ) and a mixture of $0.05 \mathrm{M}$ ammonium acetate/acetonitrile $(90 / 10 \mathrm{v} / \mathrm{v})$ at flow rate of $1.0 \mathrm{~mL} / \mathrm{min}$ as eluent. Skin uptake was expressed as MTX amount vs skin diffusion area $\left(\mu \mathrm{g} / \mathrm{cm}^{2}\right)$. 
SEM analyses of skin treated with an MSN dispersion in phosphate buffer ( $\mathrm{pH} 6.5)$, were performed, with the equipment cited above, as follows; an appropriate aliquot of suspension, containing the same amounts of silica particles present in the complex, was applied to a dermatomed porcine skin slice using a Franz diffusion cell, in the same procedure as described above. After $24 \mathrm{~h}$ of exposure, the suspension was removed and the treated skin part was reduced to small pieces using a scalpel. The substrates were then deposed on aluminum stubs by pasting the $\mathrm{SC}$ to the adhesive carbon tabs and the epidermis, which was facing upwards, was subjected to SEM observations.

\section{Results and discussion}

\subsection{Characterization of MSN}

HRTEM images of MSN are shown in Fig. 1. The ordered hexagonal mesoporous structure can be easily seen in the images, proving that the samples have a high degree of structural order, as is typical of the MCM-41-like structure.

SEM observations were performed with the purpose of investigating the surface morphology of the silica nanoparticles. As shown in Fig. 2, MSN were found to be spherical and monodispersed, with an average particle diameter of around $200 \mathrm{~nm}$, in agreement with the size claimed on the label.

Although microscopy is widely used to determine particle size, its accuracy is low as it only measures a small proportion of the particles. Dynamic light scattering (DLS), is another, widely-used method for the determination of particle size, while FFF is an elution-based, particle separation technique that can be used for determining the size distribution of various particles. The main advantage of this technique is that aggregates are investigated in situ, without any drying or further manipulation.

The mean diameter and polydispersity of MSN were therefore investigated further using the AF4 technique hyphenated to UV-Vis and DLS detectors.

AF4 is a type of flow fractionation technique and was developed by Giddings in 1966. It separates 
macromolecules and particles according to their diffusion coefficient. Similarly to chromatography, a sample is injected into a liquid stream flowing through a channel, consisting of two plates separated by a spacer. The stream drives the components along the channel and carries them to the detector. In the case of AF4, separation is achieved within the parabolic flow profile as the substrate passes through the channel, against which a perpendicular cross-flow is applied (Reschiglian et al., 2005).

The method's experimental parameters were adjusted (focusing and injection time and cross-flow rate), in order to optimize FFF separation. All tested conditions are listed in Table 2.

The UV-fractogram (Fig. 3), displays a sharp peak around 15 minutes of elution, followed by a smaller and broader signal at the end of the elution process. Overall, the average size given by the DLS-fractogram (Fig. 4), is in agreement with the results obtained from SEM observation.

\subsection{Characterization of MTX/MSN: zeta potential, loading and release studies}

This work sees MSN being evaluated for use as potential drug delivery vectors for the cutaneous application of MTX, which is widely used in the treatment of skin diseases, as a case study. The interaction of the drug with MSN has thus been investigated using zeta potential measurements, loading efficiency and release profiles. As regards the zeta potential measurements, the value of bare MSN is $-21.6( \pm 0.7) \mathrm{mV}$, which is ascribed to the negative charge that silanol groups have under a wide range of $\mathrm{pH}$ values. This value changed to $-16.1( \pm 2.3) \mathrm{mV}$ after MTX loading. Since surface charge is closely related to the electrostatic interaction between the particles in suspension, a change of zeta potential to a lower absolute value can be attributed to the fact that the drug molecules, partially deposited on the surface of the silica nanoparticles, shielded the silica surface charge after loading. Moreover, some of the free silica hydroxyl groups are involved in non-covalent bonding with MTX.

Consequently, these results provide reasonable proof of the existence of a certain interaction between the two species $\left(\mathrm{SiO}_{2}-\mathrm{MTX}\right)$. 
As reported in Table 3, the average amount of MTX loaded was estimated upon extraction with two different solvents, DMSO and phosphate buffer at $\mathrm{pH}$ 6.5, and was found to be 39.4 and 37.8\%, respectively, which is consistent with the differing polarities of the extractive media. The influence of the silica matrix on MTX was investigated by monitoring drug loading over time as it is important to evaluate the carrier's effect on the entrapped molecules when developing drug delivery systems. After 90 days of MTX/MSN stocking at RT, the loading results were 39.2\% with DMSO and 35.5\% with phosphate buffer at $\mathrm{pH} 6.5$, showing that the entrapped drug displays some stability for three months.

The release of the active ingredient from a drug delivery system is an important feature for its application. In vitro release from skin products and their subsequent permeation through an artificial membrane can generally be tested using a diffusion cell system from which the receiving medium is sampled periodically for quantitation to establish a flux profile. This type of test is an important characterization tool and is widely used for many purposes during drug development, as it is easier to implement and less costly than in vivo studies, especially for screening processes and the stability assessment of new formulations.

The release profile was investigated in this study by monitoring the transmembrane diffusion of MTX under physiological skin conditions ( $\left.\mathrm{pH} 6.5,34 \pm 1^{\circ} \mathrm{C}\right)$. As plotted in Fig. 5, the percentage of MTX detected over time in the receiving compartment follows a biphasic trend. In the first phase (0-5 h), no differences between free and entrapped MTX were observed, whereas the MTX/MSN profile was delayed compared to free MTX in the second phase (5-24 h). This difference is most likely due to the weak drug-matrix interactions that exist between the silanol groups and the drug molecules and further confirms that complexation occurred.

\subsection{Cell proliferation assay}

MTX is an immunosuppressive agent that mediates its effects on proliferating epidermal cells (Elango 
et al., 2015). We therefore examined the growth-inhibitory effect of MTX, both free and complexed, on HaCaT epidermal keratinocyte cells using the SRB assay in order to evaluate the efficacy of the MTX/MSN complex as a proper delivery system. Cells were incubated for 48 and $72 \mathrm{~h}$ with different MTX concentrations, in the $0-10000 \mathrm{nM}$ range. Moreover, the growth inhibition effect of free and complexed MTX was compared with that of bare MSN at the same concentrations. As shown in Fig. 6, the viability of HaCaT cells after $72 \mathrm{~h}$ of incubation was not affected by MSN, even at the highest concentrations tested. This finding suggests that the vehicle used in this study does not produce any toxic effect, confirming its excellent biocompatibility.

Free MTX and MTX/MSN showed the same trend; at 1 and $10 \mathrm{nM}$ they did not influence cell proliferation, however cell growth inhibition was observed when MTX concentrations were increased to 100 and $10000 \mathrm{nM}$. At $100 \mathrm{nM}$, both MTX and MTX/MSN induced comparable cell growth inhibition that was greater than $70 \%$. The same trend and inhibition extent were already achieved after $48 \mathrm{~h}$ incubation (data not shown). These results indicate that MTX is effectively delivered from the MTX/MSN complex.

\subsection{Ex-vivo experiments}

A number of theories concerning the mechanisms of permeation and retention of nanoparticulate systems are currently under discussion into the skin. Recently, it was found that particles with nanodimensions are able to penetrate the superficial layers of the SC and to accumulate in hair follicles (Lademann et al., 2015). It must be emphasized, however, that penetration through skin layers becomes more relevant in the presence of damaged skin, such as in the case of dermatitis or burns. A damaged skin barrier would not only increase the number of nanoparticles that can penetrate across the skin, but will likely also enable penetration of larger ones to occur.

The purpose of this study was, therefore, to explore whether it is possible to increase the cutaneous absorption and, consequently, the efficacy of MTX in the treatment of skin diseases by employing MCM-41-like nanoparticles as topical vectors. An ex-vivo study on porcine skin was therefore 
performed, as a predictive test, using Franz cells as a consolidated model for assessing skin penetration. This model skin was chosen due to its high affinity with human skin (Sekkat et al., 2002). Experiments were carried out using phosphate buffer, pure shea butter, glycerolipidic lotions and a number of $\mathrm{O} / \mathrm{W}$ and $\mathrm{W} / \mathrm{O}$ emulsions as the dermal formulations for the MTX-loaded silica nanoparticles. The corresponding free MTX-containing formulations were examined for comparative purposes (Fig. 7).

We shall start with formulations containing free MTX (white bars), in which differing epidermal accumulation values were observed, depending on composition. Significantly higher values were obtained in the glycerolipidic lotions $\left(6.52 \mu \mathrm{g} / \mathrm{cm}^{2}\right.$ for GL1 and $6.56 \mu \mathrm{g} / \mathrm{cm}^{2}$ for GL2, respectively), most likely because of their hydrolipidic nature and the presence of glycerol which can promote skin uptake. Conversely, it can be assumed that the high polarity of the phosphate buffer prevents MTX overcoming the hydrolipidic barrier, whereas the melting point plays a decisive role in the case of pure shea butter; being very close to the temperature of the skin, the high viscosity of this medium hampers the diffusion of the active ingredient.

Furthermore, it can be noted that while with the W/O emulsion (WO) low accumulation is obtained $\left(1.22 \mu \mathrm{g} / \mathrm{cm}^{2}\right)$, phenomenon explained by the hydrophilic nature of the drug, the $\mathrm{O} / \mathrm{W}$ emulsions containing shea butter (OW1 and OW2) reveal different accumulation values, slightly higher in the presence of Helianthus Annuus Seed Oil $\left(5.97 \mu \mathrm{g} / \mathrm{cm}^{2}\right)$ compared to Glycine Soja Oil $\left(3.91 \mu \mathrm{g} / \mathrm{cm}^{2}\right)$. The O/W emulsion, that was prepared as a control (OW3), by replacing the shea butter and the vegetable oil with mineral oil (paraffinum liquidum), exhibits lower MTX retention $\left(2.91 \mu \mathrm{g} / \mathrm{cm}^{2}\right)$ than OW1 and OW2, suggesting that shea butter may promote drug absorption by acting as a permeation enhancer, especially in combination with Helianthus Annuus Seed Oil.

Skin slices treated with formulations containing the nanosized complex (grey bars), showed higher MTX retention values than those treated with the corresponding, free-MTX-containing formulations. This finding is particularly pronounced in the cases of GL1 and OW2, which show respective 2.4and 2.8-fold increases in the skin retention of the nanoparticle-loaded drug over the free form. The 
improved MTX epidermal accumulation observed with the MTX/MSN complex may largely be related to the intercellular penetration of the nanosized vectors that may act as a local depot from which the active molecules can diffuse into the surrounding substrate. It may also be partly due to the increased contact surface that the drug has with the upper layers of the skin.

The amounts of MTX found in the receiving compartments of the Franz cells can be seen as the fraction of MTX that overcomes the epidermal layers and hence could reasonably reach the underlying dermis. As can be seen from Fig. 8, MTX applied in pure shea butter (SB), did not reach the receiving compartment because the high viscosity of this medium hampers the diffusion of the active ingredient, as reported above. Moreover, the highest permeation values were obtained with MTX loaded in MSN and vehicled in GL1 or OW2, as is in accordance with accumulation data (Fig. 7), while all the other formulations showed less permeation capacity.

In summary, ex-vivo skin results lead to the conclusion that MSN can overcome the stratum corneum and accumulate in the epidermis. Furthermore, when formulated in an appropriate semisolid medium, they even reach the receptor compartment, which can be ideally assumed as a model for the dermis. An alternative electron microscopy visualization based approach, used in addition to diffusion experiments, have allowed studies into the mechanism of particle interactions with the skin to be deepened. The advantages of SEM are numerous and include the ability to view the object of interest at low and high magnification as well as viewing the entire object to give $3 \mathrm{D}$ information on structure and morphology (Goldstein et al., 2014). Boonen J. and co-workers have demonstrated, using SEM, that $3 \mu \mathrm{m} \mathrm{SiO} 2$ particles can penetrate into the skin from the $\mathrm{SC}$, over the living epidermal layers (Boonen et al., 2011). In this study, porcine skin samples have been examined by SEM $24 \mathrm{~h}$ after MSN application.

Fig. 9 shows the SEM images of the epidermal side of ex-vivo dermatomed porcine skin. 24 hours after exposure to an aqueous MSN dispersion (Fig. 9b), silica aggregates (white spots, red circles), with a wide dimensional micrometric range were observed. Unlike most other particle skin studies, these preliminary findings can therefore lead to the reasonable hypothesis that the bare MSN tested 
herein can overcome SC and reach the deeper epidermal layers. Moreover, the large dimensions of the aggregates detected on the epidermal side suggest that silica precipitation and particle aggregation occurred in the deeper layers of the skin, as aggregates of this size cannot penetrate across the SC. The formation of these aggregates may slow the systemic absorption of silica, while, on the other hand, it may also lead to the formation of a reservoir in the epidermal layers that enables the prolonged release of the entrapped drug, which may eventually lead to the desired increased local effects.

\section{Conclusions}

MTX is widely used to treat a vast spectrum of skin conditions. Systemic administration has been the most commonly studied approach, whereas dermal and transdermal delivery have not seen such intensive investigation. This study describes the preparation of an MTX/MSN inclusion complex and its fate when topically applied to the skin.

Cell proliferation assays, performed on epidermal keratinocyte HaCaT cells, have highlighted the biocompatibility of the vehicle, which was devoid of toxicity even at the highest concentrations tested, and the fact that the free and complexed forms of MTX evoke similar biological responses.

A series of formulations has been tested ex-vivo on porcine skin using Franz cells and it was observed that MTX retention is significantly enhanced by its inclusion in MSN. Furthermore, SEM analyses revealed traces of the nanoparticles on the epidermal side of the dermatomed skin slices, which lends weight to the hypothesis that MSN accumulates in the deeper layers of the epidermis. Franz cell trials and SEM analyses gave comparable results and the results of these two techniques taken together allow us to speculate as to the cutaneous absorption of MSN.

In summary, we have proposed a drug delivery system with a unique mechanism for topically applied MTX, which is comprised of MTX-loaded MSN and capable of delivering the drug to the deeper layers of the epidermis. The skin absorption of the drug is significantly enhanced by the addition of shea butter, which was found to act as a penetration enhancer whose effectiveness depended on the 
kind of vegetable oil used.

The in vitro preliminary findings described above thus suggest that using MSN in combination with a proper semisolid formulation could be a promising strategy for the dermal delivery of MTX.

\section{Acknowledgements}

The authors are grateful to Dr. C. Castagnoli for kindly providing shea butter.

This research has been carried out with the financial support of the University of Torino [Fondi di Ricerca Locale (ex 60\%) 2014, 2015].

\section{References}

Abbaszad Rafi, A., Mahkam, M., Davaran, S., Hamishehkar, H., 2016. A Smart pH-responsive NanoCarrier as a Drug Delivery System: A hybrid system comprised of mesoporous nanosilica MCM-41 (as a nano-container) \& a $\mathrm{pH}$-sensitive polymer (as smart reversible gatekeepers): Preparation, characterization and in vitro release studies of an anti-cancer drug. Eur. J. Pharm. Sci. 93, 64-73.

Alexa, I.F., Pastravanu, C.G., Ignat, M., Popovici, E., 2013. A comparative study on long-term MTX controlled release from intercalated nanocomposites for nanomedicine applications. Colloids Surfaces B: Biointerfaces 106, 135-139.

Alvarez-Figueroa, M.J., Blanco-Méndez, J., 2001. Transdermal delivery of methotrexate: Iontophoretic delivery from hydrogels and passive delivery from microemulsions. Int. J. Pharm. 215, $57-65$.

Boonen, J., Baert, B., Lambert, J., De Spiegeleer, B., 2011. Skin penetration of silica microparticles. Pharmazie 66, 463-464.

Cipriani, P., Ruscitti, P., Carubbi, F., Liakouli, V., Giacomelli, R., 2014a. Methotrexate: An old new drug in autoimmune disease. Expert Rev. Clin. Immu. 10, 1519-1530.

Cipriani, P., Ruscitti, P., Carubbi, F., Liakouli, V., Giacomelli, R., 2014b. Methotrexate in 
Rheumatoid Arthritis: Optimizing Therapy Among Different Formulations. Current and Emerging Paradigms. Clin. Ther. 36, 427-435.

Curtis, J.R., Bykerk, V.P., Aassi, M., Schiff, M., 2016. Adherence and persistence with methotrexate in rheumatoid arthritis: A systematic review. J. Rheumatol. 43, 1997-2009.

Elango, T., Thirupathi, A., Subramanian, S., Dayalan, H., Gnanaraj, P., 2015. Methotrexate normalized keratinocyte activation cycle by overturning abnormal keratins as well as deregulated inflammatory mediators in psoriatic patients. Clin. Chim. Acta 451, 329-337.

Garg, N.K., Singh, B., Tyagi, R.K., Sharma, G., Katare, O.P., 2016. Effective transdermal delivery of methotrexate through nanostructured lipid carriers in an experimentally induced arthritis model. Colloids Surfaces B: Biointerfaces 147, 17-24.

Goldstein, A., Soroka, Y., Frušić-Zlotkin, M., Popov, I., Kohen, R., 2014. High resolution SEM imaging of gold nanoparticles in cells and tissues. J. Microsc. 256, 237-247.

Herfarth, H.H., Kappelman, M.D., Long, M.D., Isaacs, K.L., 2016. Use of Methotrexate in the Treatment of Inflammatory Bowel Diseases. Inflamm. Bowel Dis. 22, 224-233.

Hess, J.A., Khasawneh, M.K., 2015. Cancer metabolism and oxidative stress: Insights into carcinogenesis and chemotherapy via the non-dihydrofolate reductase effects of methotrexate. BBA Clinical 3, 152-161.

Javadzadeh, Y., Hamishehkar, H., 2011. Enhancing percutaneous delivery of methotrexate using different types of surfactants. Colloids Surfaces B: Biointerfaces 82, 422-426.

Kim, A., Lee, J.E., Jang, W.S., Lee, S.J., Park, S., Kang, H.J., Lee, S.S., 2012. A combination of methotrexate and irradiation promotes cell death in NK/T-cell lymphoma cells via down-regulation of NF-кB signaling. Leukemia Res. 36, 350-357.

Lademann, J., Knorr, F., Richter, H., Jung, S., Meinke, M.C., Rühl, E., Alexiev, U., Calderon, M., Patzelt, A., 2015. Hair follicles as a target structure for nanoparticles. J. Innov. Opt. Heal. Sci. 8, 1530004.

Li, D., Yang, Z., Kang, P., Xie, X., 2016. Subcutaneous administration of methotrexate at high doses 
makes a better performance in the treatment of rheumatoid arthritis compared with oral administration of methotrexate: A systematic review and meta-analysis. Semin. Arthritis Rheum. 45, 656-662.

Muhammad, Z., Raza, A., Ghafoor, S., Naeem, A., Naz, S.S., Riaz, S., Ahmed, W., Rana, N.F., 2016. PEG capped methotrexate silver nanoparticles for efficient anticancer activity and biocompatibility. Eur. J. Pharm. Sci. 91, 251-255.

Pan, Z., Yang, G., He, H., Zhao, G., Yuan, T., Li, Y., Shi, W., Gao, P., Dong, L., Li, Y., 2016. Concurrent radiotherapy and intrathecal methotrexate for treating leptomeningeal metastasis from solid tumors with adverse prognostic factors: A prospective and single-arm study. Int. J. Cancer 139, 1864-1872.

Peruzynska, M., Szelag, S., Trzeciak, K., Kurzawski, M., Cendrowski, K., Barylak, M., Roginska, D., Piotrowska, K., Mijowska, E., Drozdzik, M., 2016. In vitro and in vivo evaluation of sandwichlike mesoporous silica nanoflakes as promising anticancer drug delivery system. Int. J. Pharm. 506, 458-468.

Quist, S.R., Quist, J., Birkenmaier, J., Stauch, T., Gollnick, H.P., 2016. Pharmacokinetic profile of methotrexate in psoriatic skin via the oral or subcutaneous route using dermal microdialysis showing higher methotrexate bioavailability in psoriasis plaques than in non-lesional skin. JEADV 30, 15371543.

Reschiglian, P., Zattoni, A., Roda, B., Michelini, E., Roda, A., 2005. Field-flow fractionation and biotechnology. Trends Biotechnol. 23, 475-483.

Sapino, S., Ugazio, E., Gastaldi, L., Miletto, I., Berlier, G., Zonari, D., Oliaro-Bosso, S., 2015. Mesoporous silica as topical nanocarriers for quercetin: Characterization and in vitro studies. Eur. J. Pharm. Biopharm. 89, 116-125.

Sekkat, N., Kalia, Y.N., Guy, R.H., 2002. Biophysical study of porcine ear skin in vitro and its comparison to human skin in vivo. J. Pharm. Sci. 91, 2376-2381.

Ugazio, E., Gastaldi, L., Brunella, V., Scalarone, D., Jadhav, S.A., Oliaro-Bosso, S., Zonari, D., Berlier, G., Miletto, I., Sapino, S. 2016. Thermoresponsive mesoporous silica nanoparticles as a 
carrier for skin delivery of quercetin. Int. J. Phar. 511, 446-454.

Vallet-Regí, M., Balas F., Arcos, D. 2007. Mesoporous materials for drug delivery. Angew. Chem., Int. Ed., 2007, 46, 7548-7558.

Yélamos, O., Català, A., Vilarrasa, E., Roé, E., Puig, L., 2014. Acute severe methotrexate toxicity in patients with psoriasis: A case series and discussion. Dermatology 229, 306-309.

Yélamos, O., Puig L. 2015. Systemic methotrexate for the treatment of psoriasis. Expert Rev. Clin. Immunol. 11, 553-565. 
Table 1. List of dermal formulations tested in ex vivo experiments

\begin{tabular}{|c|c|c|}
\hline Medium & Composition & Sign \\
\hline Phosphate buffer (pH 6.5) & $\mathrm{KH}_{2} \mathrm{PO}_{4} / \mathrm{Na}_{2} \mathrm{HPO}_{4}(0.07 \mathrm{M})$ in water & $\mathrm{PB}$ \\
\hline Shea butter & 100.00\% Butyrospermum Parkii butter & SB \\
\hline Glycerolipidic lotion 1 & $\begin{array}{l}70.00 \% \text { Butyrospermum Parkii butter, } 20.00 \% \text { Glycine } \\
\text { Soja Oil, } 10.00 \% \text { Glycerin }\end{array}$ & OL1 \\
\hline Glycerolipidic lotion 2 & $\begin{array}{l}70.00 \% \text { Butyrospermum Parkii butter, 20.00\% } \\
\text { Helianthus Annuus Seed Oil, } 10.00 \% \text { Glycerin }\end{array}$ & OL2 \\
\hline W/O emulsion & $\begin{array}{l}\text { Phase A: } 5.20 \% \text { Diethylhexylcyclohexane; } 5.20 \% \\
\text { Cetearyl Isononanoate; 5.20\% C10-18 Triglycerides; } \\
5.20 \% \text { Mineral oil and Lanolin Alcohol; 5.20\% } \\
\text { Polyglyceryl 2-Dipolyhydroxystearate. Phase B: } \\
67.70 \% \text { Aqua; 5.20\% Glycerin; 0.70\% Magnesium } \\
\text { Sulphate; 0.40\% Phenoxyethanol, Methylparaben, } \\
\text { Butylparaben, Ethylparaben, Propylparaben, }\end{array}$ & WO \\
\hline $\begin{array}{l}\mathrm{O} / \mathrm{W} \text { emulsion } 1 \\
\mathrm{O} / \mathrm{W} \text { emulsion } 2\end{array}$ & $\begin{array}{l}\text { Phase A: } 3.50 \% \text { Cetearyl Alcohol and Cetearyl } \\
\text { Glucoside; } 2.00 \% \text { Potassium Cetyl Phosphate; } 10.00 \% \\
\text { Butyrospermum Parkii butter; } 4.00 \% \text { Dimethicone; } \\
\text { 10.00\% Glycine Soja Oil (OW1) or Helianthus } \\
\text { Annuus Seed Oil (OW 2). Phase B: } 66.20 \% \text { Aqua; } \\
\text { 4.00\% Glycerin; } 0.30 \% \text { Imidazolidinyl urea }\end{array}$ & $\begin{array}{l}\text { OW1 } \\
\text { OW2 }\end{array}$ \\
\hline $\mathrm{O} / \mathrm{W}$ emulsion 3 & $\begin{array}{l}\text { Phase A: } 3.50 \% \text { Cetearyl Alcohol and Cetearyl } \\
\text { Glucoside; } 2.00 \% \text { Potassium Cetyl Phosphate; } 4.00 \% \\
\text { Dimethicone; } 20.00 \% \text { Paraffinum liquidum. Phase B: } \\
\text { 66.20\% Aqua; } 4.00 \% \text { Glycerin; } 0.30 \% \text { Imidazolidinyl } \\
\text { urea }\end{array}$ & OW3 \\
\hline
\end{tabular}


Table 2. AF4 runs used in the analysis of MSN*

\begin{tabular}{|l|l|l|l|}
\hline Run & Cross-flow gradient & Focus-flow & Focus+Injection Time \\
\hline 1 & $1.0-0 \mathrm{~mL} / \mathrm{min}$ in $20 \mathrm{~min}$ & $1.30 \mathrm{~mL} / \mathrm{min}$ & $3 \mathrm{~min}$ \\
\hline 2 & $0.2-0 \mathrm{~mL} / \mathrm{min}$ in $20 \mathrm{~min}$ & $1.30 \mathrm{~mL} / \mathrm{min}$ & $6 \mathrm{~min}$ \\
\hline
\end{tabular}

*detector and injection flow rates were 1.0 and $0.2 \mathrm{~mL} / \mathrm{min}$, respectively 
Table 3. MTX loading conditions and values

\begin{tabular}{|c|c|c|c|}
\hline Sample & $\begin{array}{l}\text { Extraction } \\
\text { conditions }\end{array}$ & $\begin{array}{c}\text { Loading by UV-Vis } \\
(\% \mathrm{w} / \mathrm{w})\end{array}$ & $\begin{array}{l}\text { Loading by UV-Vis } \\
\text { after } 90 \text { days }(\% \text { w/w) }\end{array}$ \\
\hline \multirow[b]{2}{*}{ MTX/MSN (1/1 w/w) } & $\begin{array}{c}\text { DMSO } \\
20^{\circ} \mathrm{C}, 24 \mathrm{~h}\end{array}$ & $39.4( \pm 1.1)$ & $39.2( \pm 1.4)$ \\
\hline & $\begin{array}{l}\text { Phosphate } \\
\text { buffer } \\
20^{\circ} \mathrm{C}, 24 \mathrm{~h}\end{array}$ & $37.8( \pm 1.2)$ & $35.5( \pm 0.98)$ \\
\hline
\end{tabular}




\section{Figure captions}

Fig. 1: TEM observations of MSN at different magnifications: a) 15000× and b) $80000 \times$.

Fig. 2: SEM images of MSN at different magnifications: a) 5000× and b) 10000×.

Fig. 3: AF4-UV fractogram of MSN: run 1 (dotted line) and run 2 (solid line).

Fig. 4: AF4-DLS fractogram of MSN (run 2) detected at a $173^{\circ}$ angle.

Fig. 5: Diffusion profiles of MTX through a cellulose membrane. A free MTX solution (grey, circle), and a complex dispersion (black, square), in phosphate buffer (pH 6.5) were tested at $34 \pm 1$ ${ }^{\circ} \mathrm{C}$. Each bar represents the mean \pm SD obtained in three independent experiments.

Fig. 6: Effect of MTX, MTX/MSN and MSN on HaCaT cell proliferation after $72 \mathrm{~h}$ of incubation. The concentration of silica nanoparticles is shown in the upper $\mathrm{x}$-axis, while the concentration of MTX, either free or complexed, is reported in the lower x-axis. Cell growth is expressed as \% T/C (mean OD of treated cells/mean OD of control cells $\times 100)$. Values are mean \pm SD (n $=3$ wells/condition) of two independent experiments.

Fig. 7: Amounts $\left(\mu \mathrm{g} / \mathrm{cm}^{2}\right)$ of MTX accumulated in dermatomed skin (stratum corneum and epidermis), as recovered by solvent extraction $24 \mathrm{~h}$ after application.

Fig. 8: Amounts $\left(\mu \mathrm{g} / \mathrm{cm}^{2}\right)$ of MTX permeated into receptor compartments, revealed $24 \mathrm{~h}$ after application.

Fig. 9: SEM images at 37× magnification of a) untreated and b) MSN-treated skin (epidermal side). 

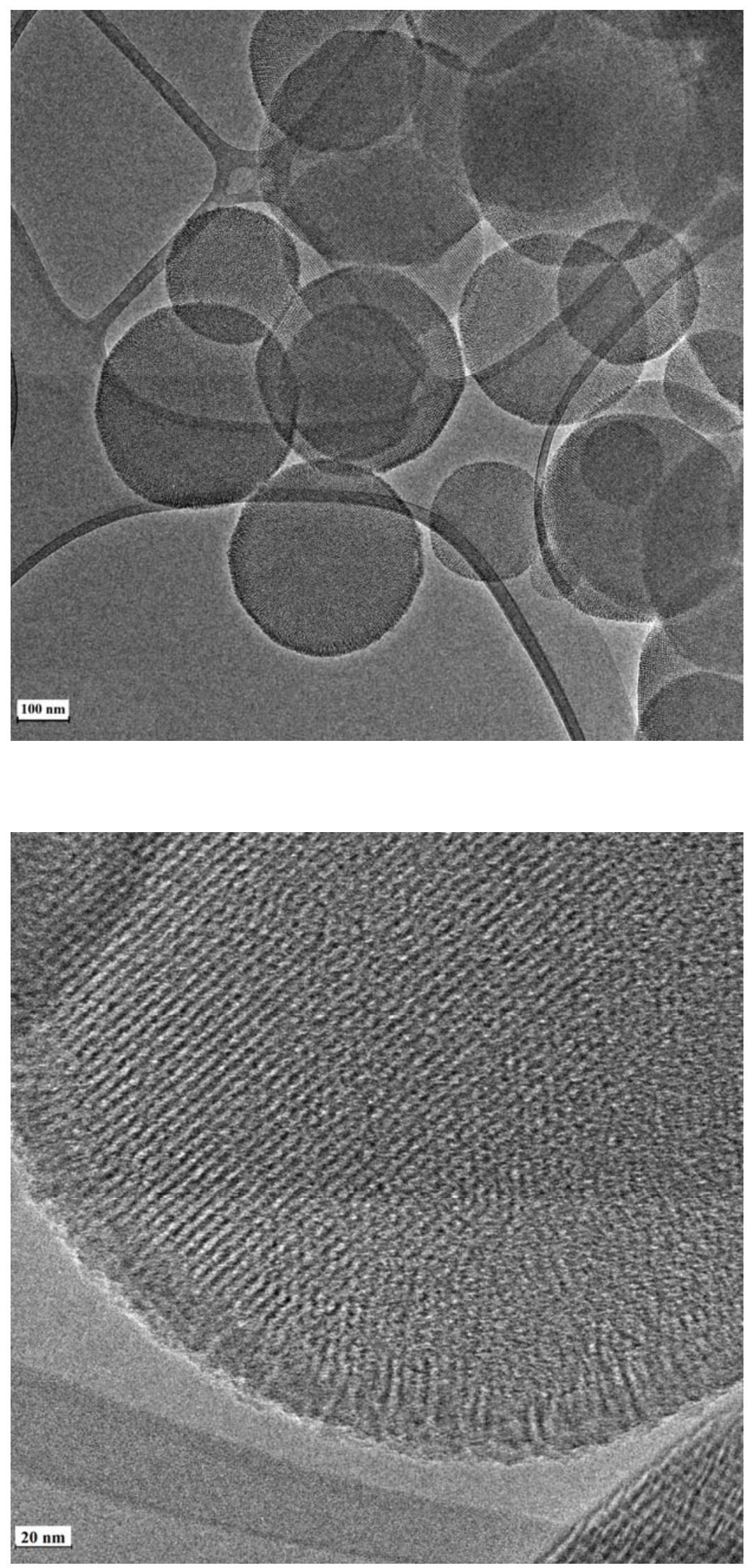

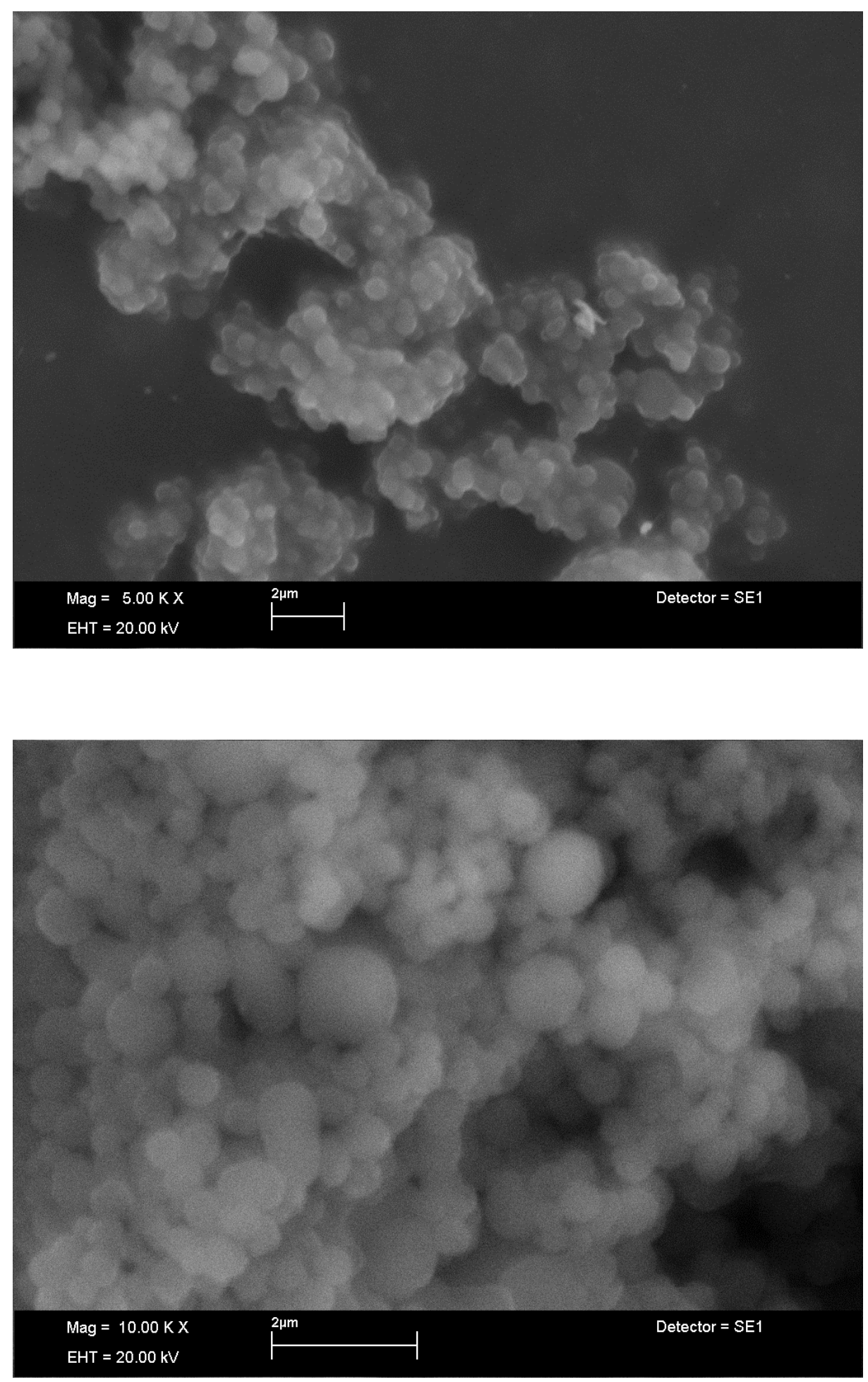


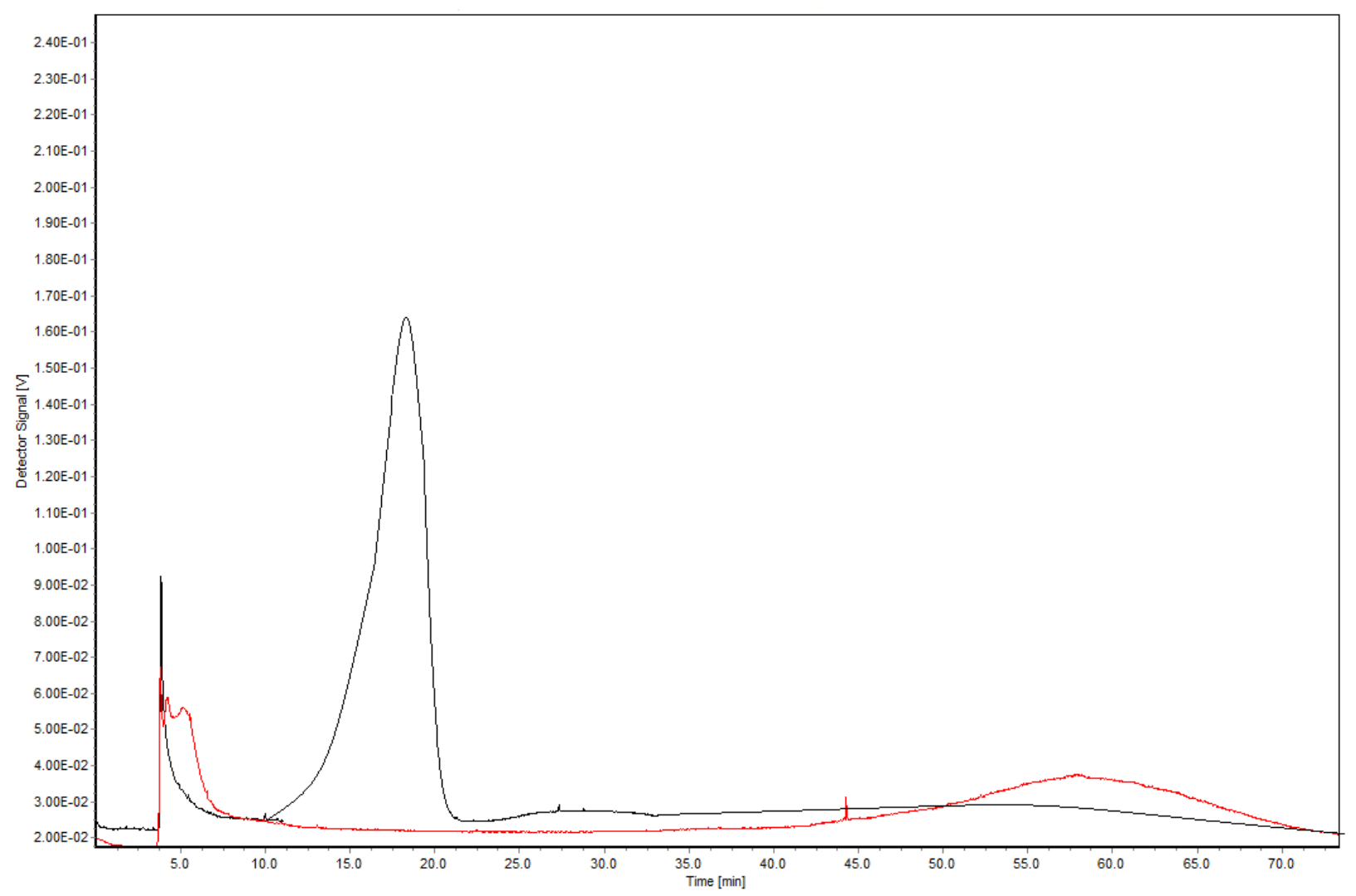


Flow trace v Time

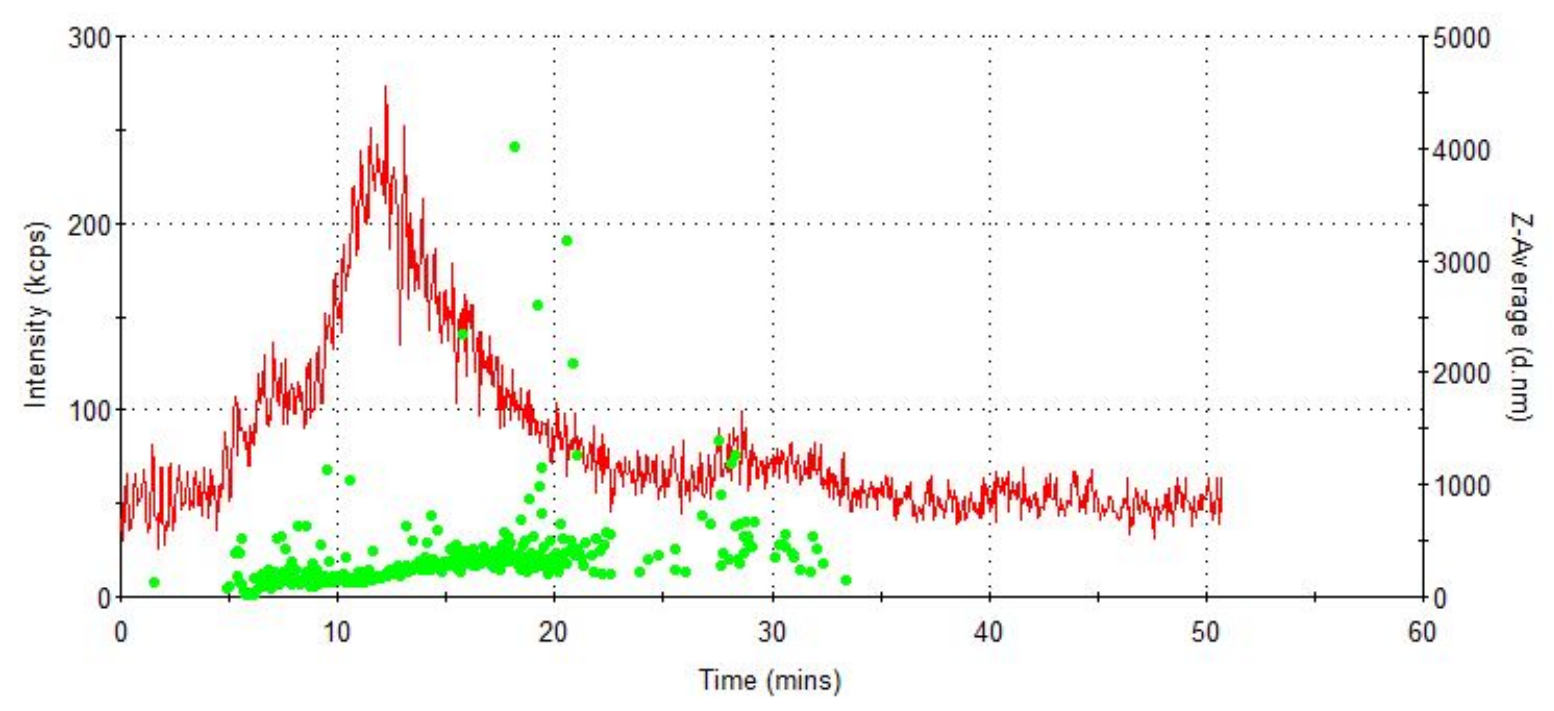

Record 1: MCM-41 sigma 1 (Intensity)

Record 1: MCM-41 sigma 1 (Z-Average) 


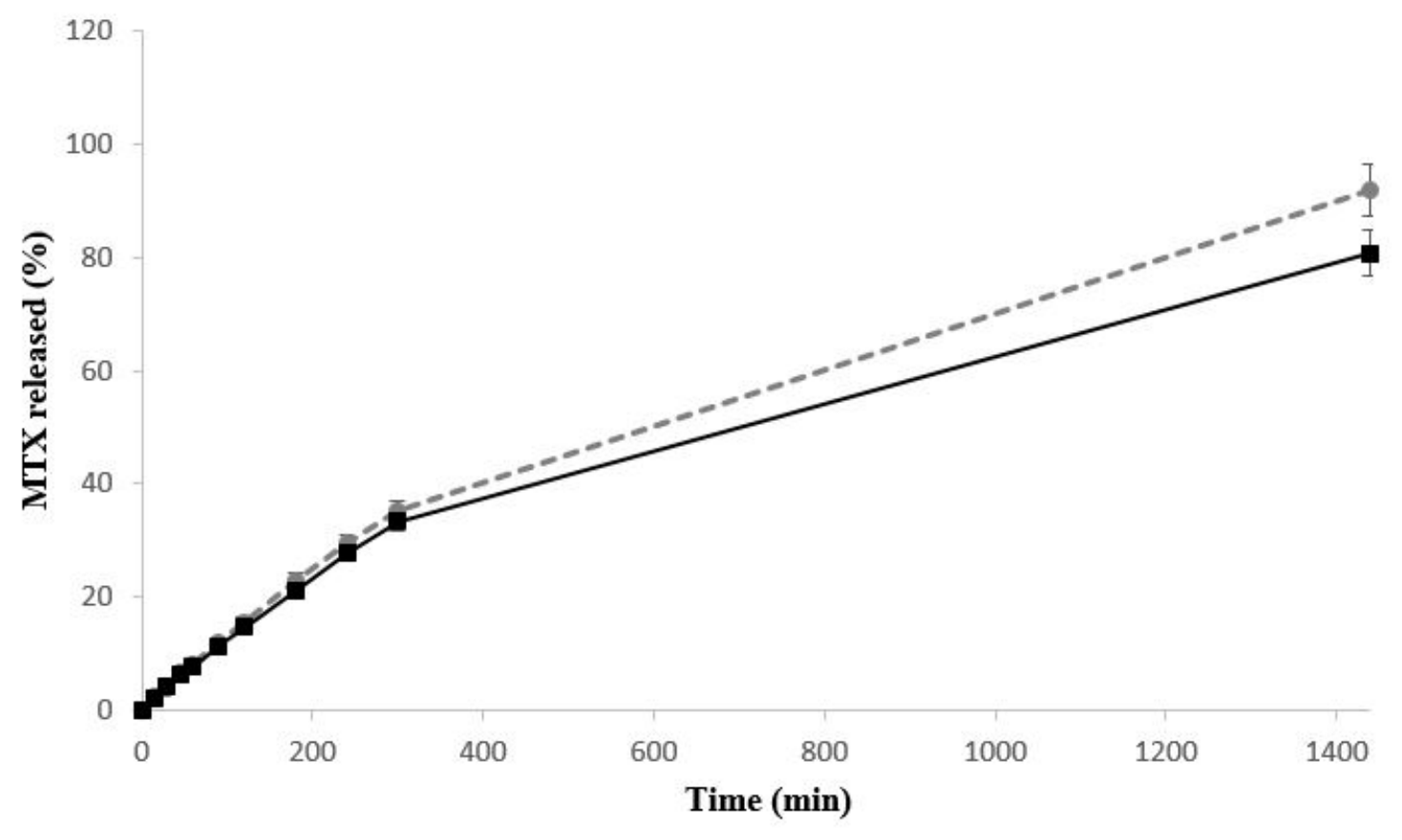




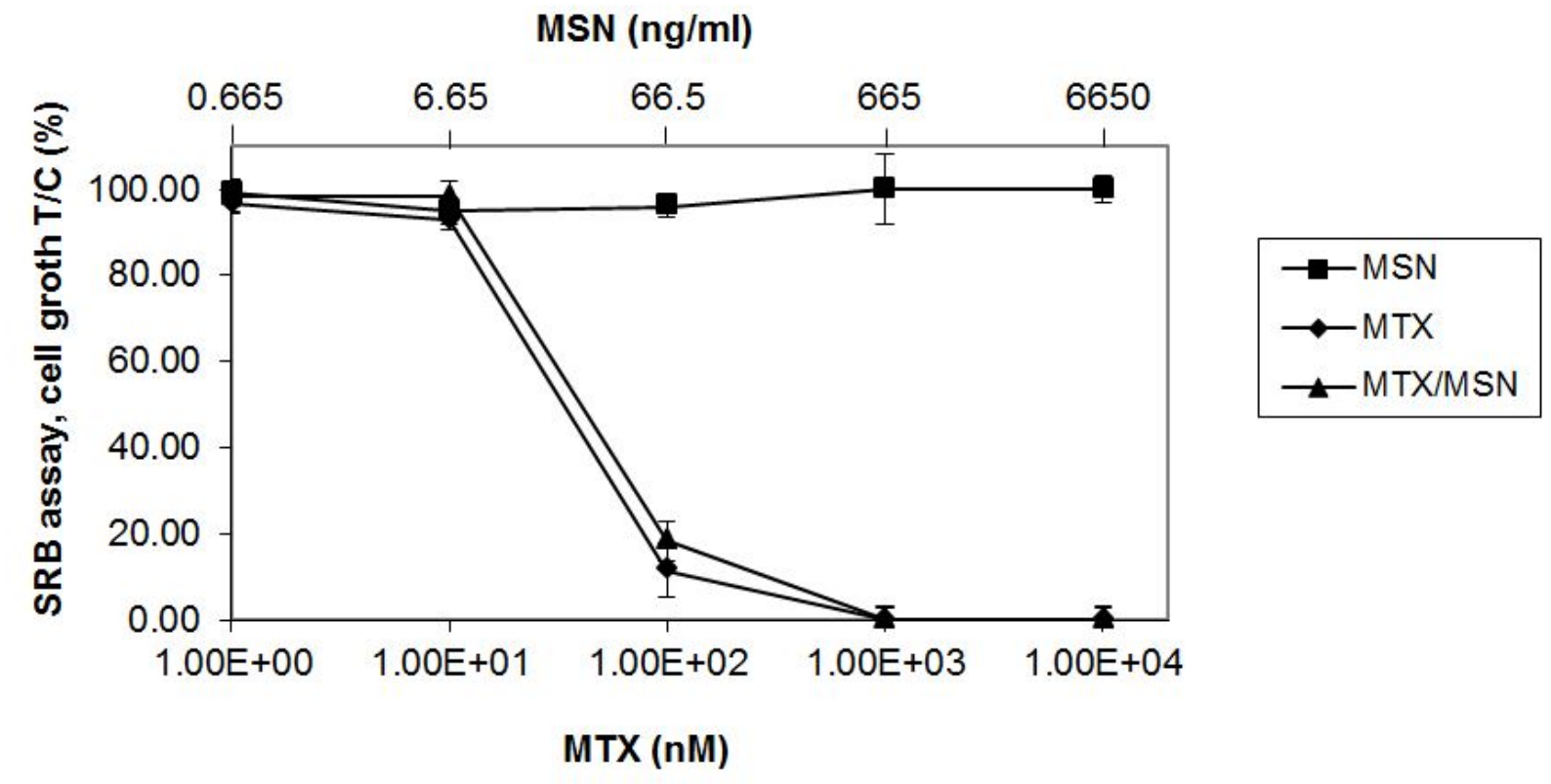




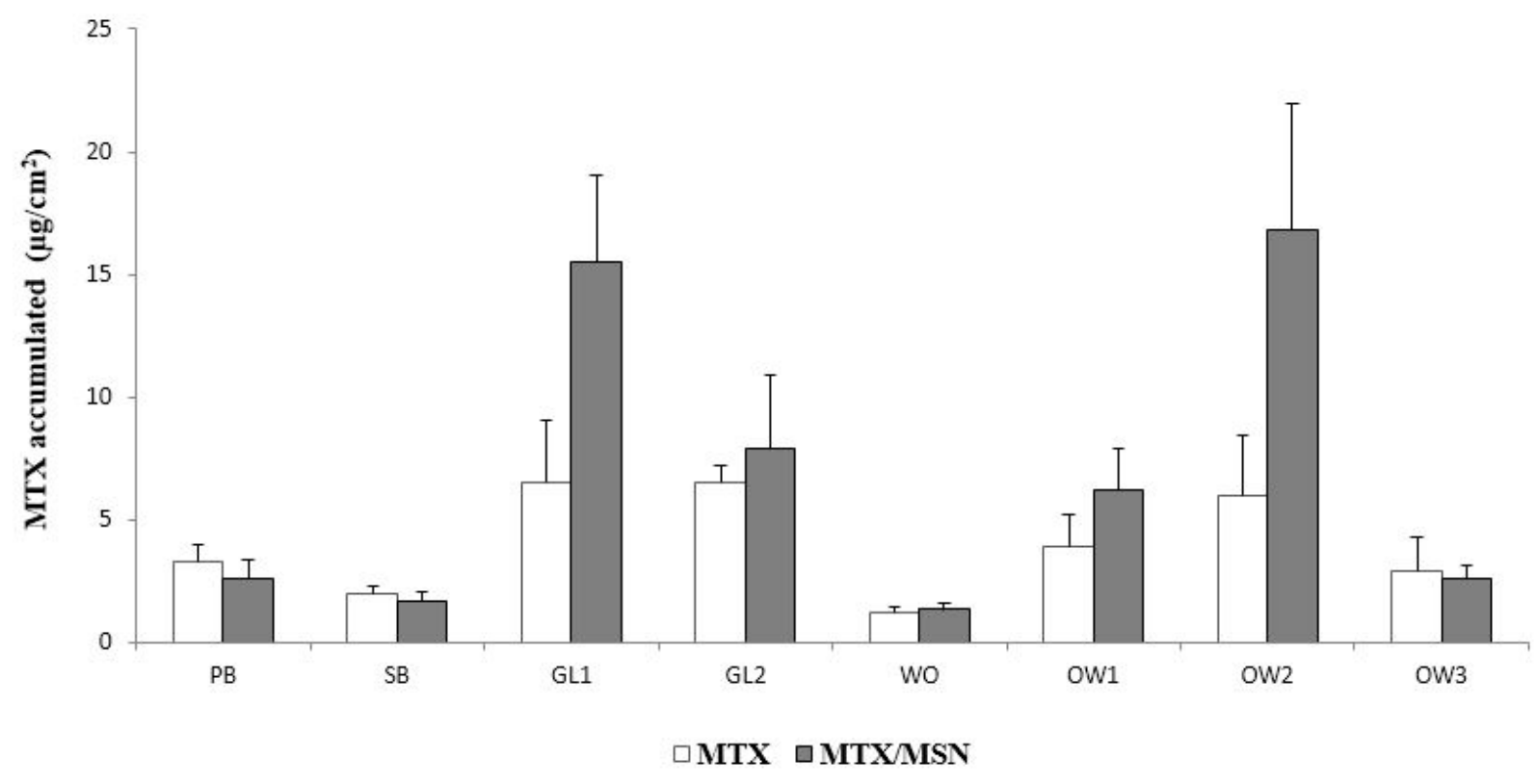




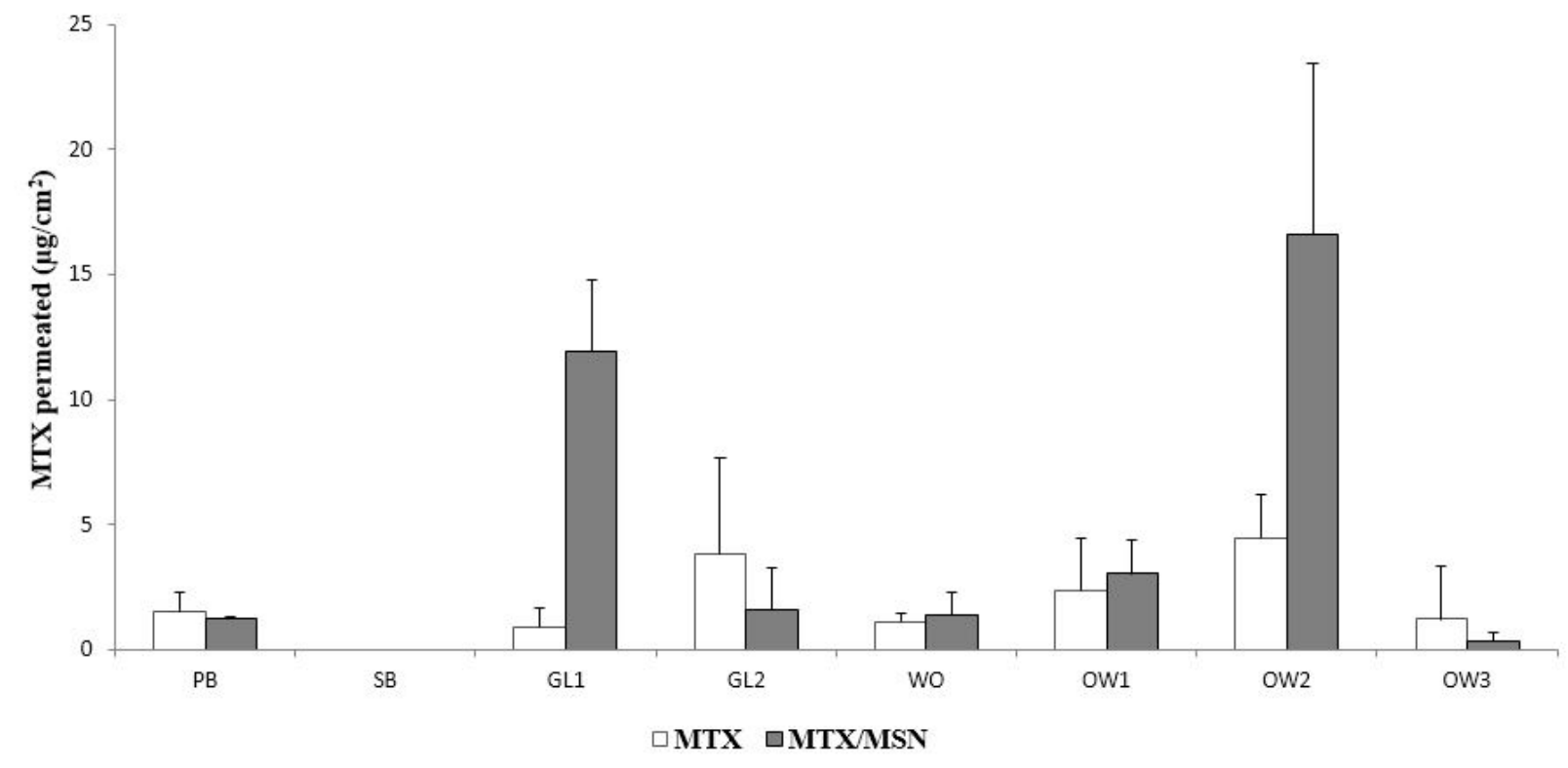



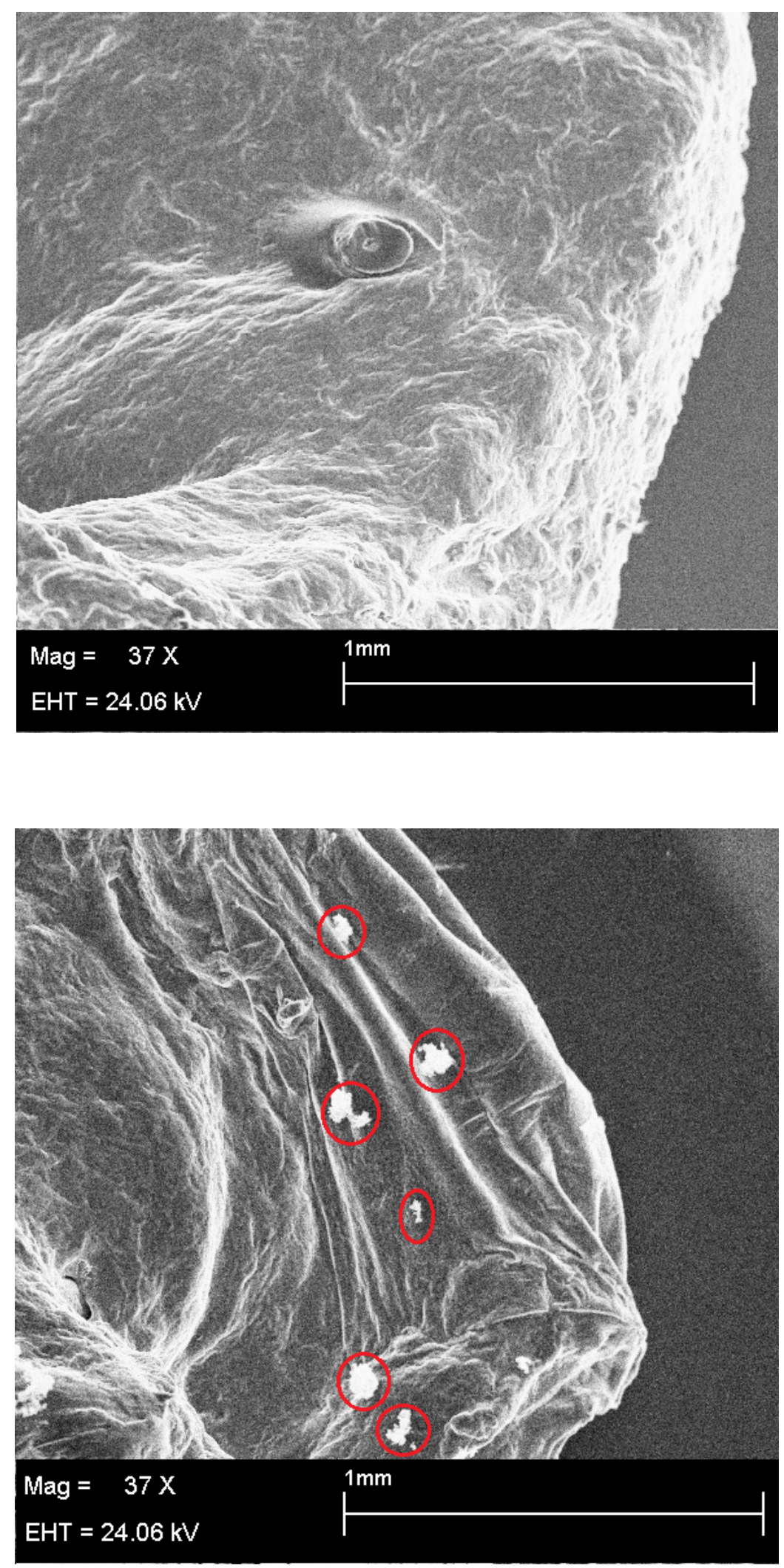


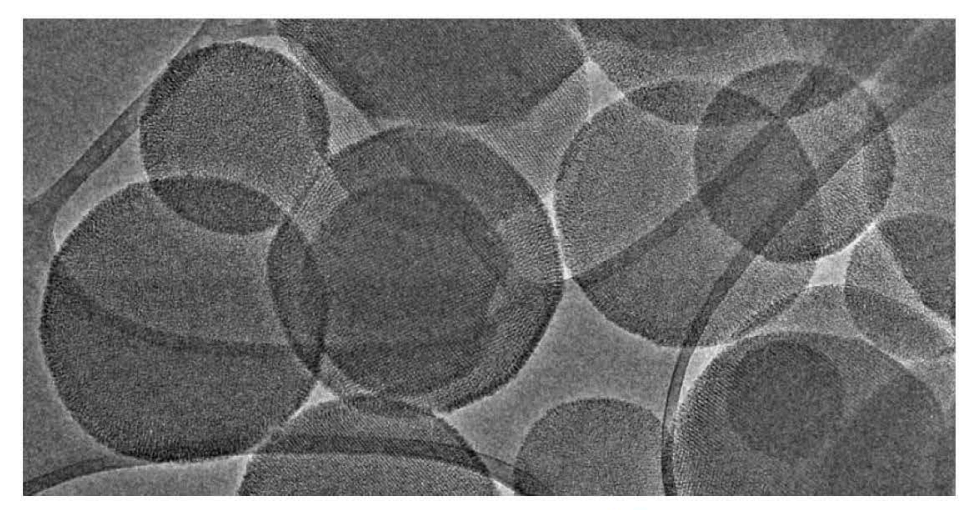

MCM-41 nanoparticles
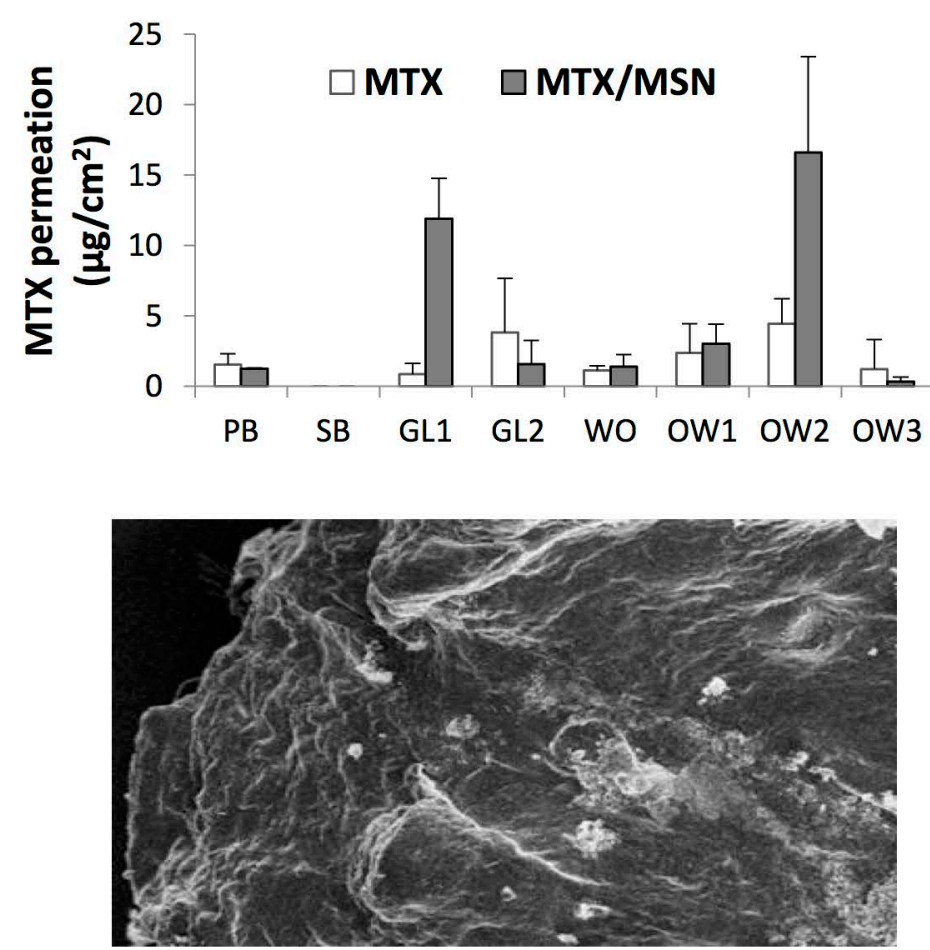

MSN-treated skin
$-2-12$

Methotrexate

complexation

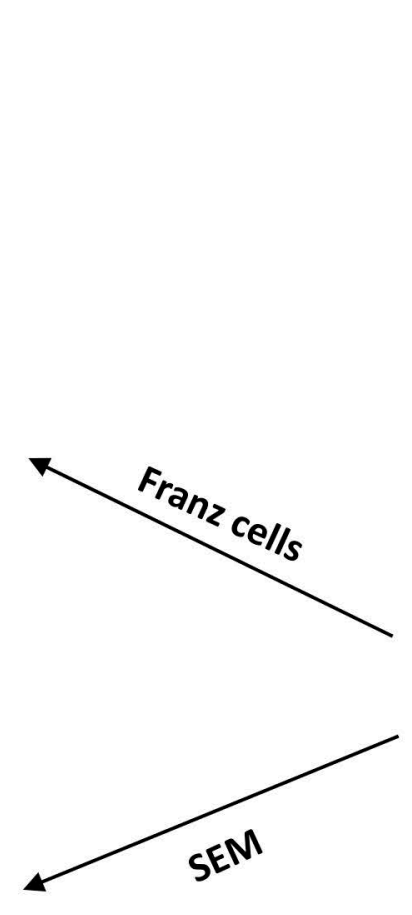

Dermal

formulations

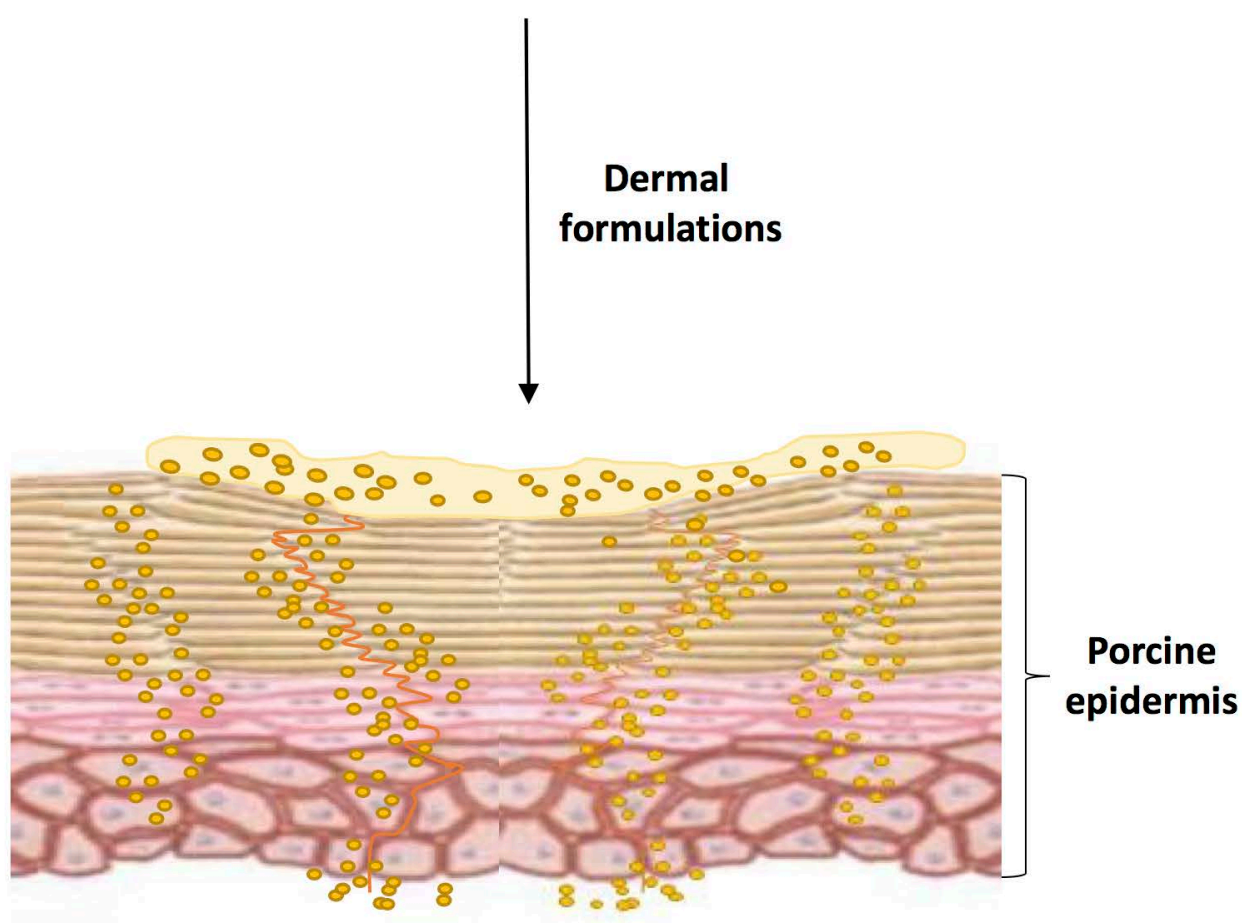

Porcine pidermis 